\title{
State-of-Art-Review: Latest Advancements in Seismic Isolation of Structures
}

\author{
Syed Emad Uddin Ahmad ${ }^{1, *}$, Khalid Moin ${ }^{2}$, Rehan Ahmad Khan ${ }^{3}$ \\ ${ }^{1}$ Research Scholar, Department of Civil Engineering, Jamia Millia Islamia, New Delhi 110025, India \\ ${ }^{2}$ Professor, Department of Civil Engineering, Jamia Millia Islamia, New Delhi 110025, India \\ ${ }^{3}$ Professor, Department of Civil Engineering, Faculty of Engineering, Z.H. College of Engineering Aligarh Muslim University, \\ Aligarh U.P., India
}

Received July 30, 2021; Revised December 13, 2021; Accepted December 27, 2021

\section{Cite This Paper in the following Citation Styles}

(a): [1] Syed Emad Uddin Ahmad, Khalid Moin, Rehan Ahmad Khan, "State-of-Art-Review: Latest Advancements in Seismic Isolation of Structures," Civil Engineering and Architecture, Vol. 10, No. 2, pp. 567-583, 2022. DOI: 10.13189/cea.2022.100215.

(b): Syed Emad Uddin Ahmad, Khalid Moin, Rehan Ahmad Khan (2022). State-of-Art-Review: Latest Advancements in Seismic Isolation of Structures. Civil Engineering and Architecture, 10(2), 567-583. DOI: 10.13189/cea.2022.100215.

Copyright $\bigcirc 2022$ by authors, all rights reserved. Authors agree that this article remains permanently open access under the terms of the Creative Commons Attribution License 4.0 International License

\begin{abstract}
Seismic isolation is effected by providing an interface between the foundations of the building and superstructure which may consist of stories above the ground level by inserting devices. Those are meant to reduce the effect of ground motions generated by an earthquake or/ and wind load. In this process, the period of the whole structure including base isolators is elongated so that ground waves containing large energy contents in the horizontal components of the earthquake may be deflected conveniently. An updated state-of-art review of isolation techniques and the design of isolated buildings is presented in this paper. The research findings in the comprehensive form are extracted out of the large volume of research papers published during the last five decades, where only some limited quality papers are selected for the preparation of this manuscript. The review generally covered papers on the analysis and design of structures with base isolation. Review is not confined to buildings with friction pendulum isolators only, but also includes the study of structural response to some other types of base isolators and dampers to seismic attacks.
\end{abstract}

Keywords Isolation Techniques, Earthquake, Friction Pendulum Isolators, Base Isolated Buildings

\section{Introduction}

Considerable research work has been carried out during the last five decades in the field of earthquake engineering especially base isolation of structures. To mention some authors of repute who contributed continuously in the field of Earthquake Engineering are Constantinou et al. [12]; Su et al. [41]; Zayas et al. [44]; Tsopelas et al. [42]; Al-Hussaini et al. [3]; Jangid et al. [23]; Kelly et al. [25]; Matsagar et al. [28]; Dolce et al.[14]; Panchal et al. [35]; Cardone et al. [10]; Islam et al. [21]; Mazza et al. [ 29] and many more. It is desirable to review the important findings presented in various research papers which generally appear regularly in this field in various journals, workshops, and conferences. The objective of these reviews is the dissemination of knowledge among academia, scientific groups, and engineers who are involved in the design, implementation, and development of base isolation bearings in different types of structures throughout the world.

\section{Base Isolators}

Earlier designs have focused on increasing the ductility of structures to protect them from seismic attacks. Other measures would be to reduce stiffness irregularity of the building (soft story), plan irregularity and vertical irregularity. Reducing lumped masses helps in protective design. Also, weak-beam and strong columns ensure that the deformation takes place in beams rather than columns which safeguard the sudden collapse of building in the event of an earthquake. But all these measures have a limited scope of protection from earthquakes. The concept 
of base isolation (BI) has of late caught the attention of engineers and scientists. Different types of base isolators were proposed.

\section{Purpose of Base Isolation}

The purpose of base isolation is to thwart the onslaught of the earthquake on civil and defense structures. Earthquakes and wind loads require the careful seismic design of structures. The approach of base isolation is to reduce the base shear and accelerations transmitted to superstructures due to earthquakes. This is done by modifying the period of base-isolated building such that large energy content components of horizontal waves generated by the earthquake are deflected from the structure as shown in Fig.1.

\section{Types of Isolator Bearings}

It can be seen from Fig. 1 that acceleration peaks due to earthquakes occur during the period of 0 to 1 second (approximately) which is generally the case for conventional buildings of low and medium heights. Due to the introduction of base isolators in the structures, the natural period of buildings is increased so that it falls at such values where the acceleration intensity is considerably diminished (Fig.1).

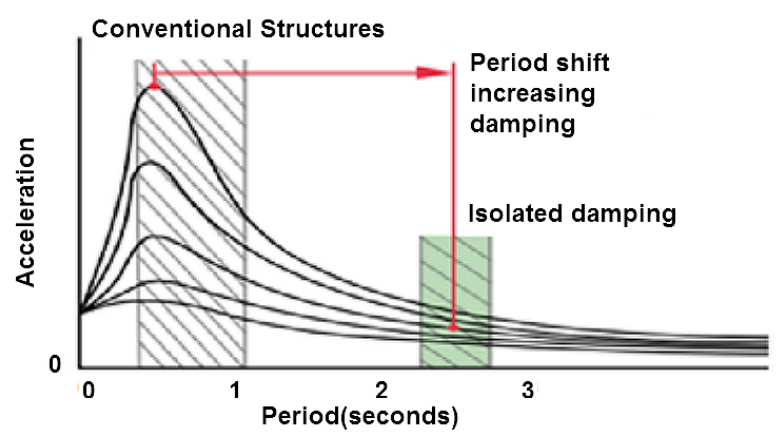

Figure 1. Plots of pseudo-spectral accelerations

Flat surface Sliding Bearings

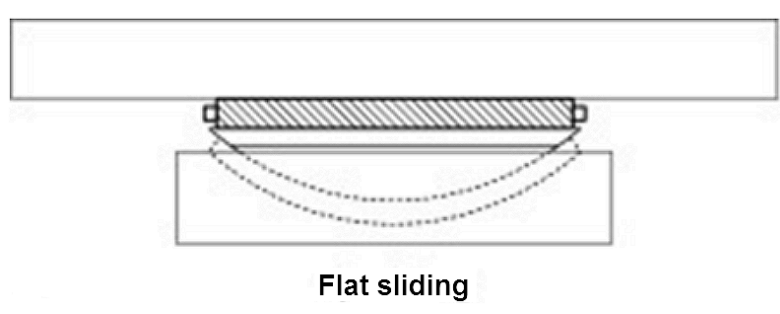

Figure 2. Flat Surface slider bearing

The Sliding systems are frequently used as base isolators in seismically designed buildings. This category consists of Flat Surface Sliding systems and Curved Surface Sliding systems (also known as Friction Pendulum type base isolators). The Flat Sliding bearing system of base isolators works on the principle of sliding element (with some known value of friction coefficient) which is placed between the foundation and the superstructure. Its purpose is to reduce the seismic forces and corresponding accelerations produced by the earthquake whenever it happens. The system under discussion is depicted in Fig.2. There is no facility for providing restoring force in this isolator as its hysteretic curve has a rectangular shape. To introduce the effect of restoring force in this type of base isolator, it can be used in combination with LRBs or HDRBs Kelly [25]. In this type of bearing PTFT disk is placed in a slot in a steel plate where this assembly slides against another stainless steel surface. For cushioning purposes, a rubber pad is used with the PTFE disk. The flat surface slider is cheaper compared to elastomeric base isolators Taylor et al. [43]. Flat sliding bearings have been in use for a long time in bridges Skinner et al. [6].

\section{Friction Pendulum Bearings}

The Friction Pendulum (base isolator) Systems (FPS) are robust types of equipment (Fig.3) that are used to reduce the effect of massive lateral forces on the superstructure caused by medium and high-intensity earthquakes. Their basic purpose is to increase the fundamental period of the superstructure with the help of an increased radius of curvature of the FPS base isolator. The biggest advantage of FPS bearing is its restoring force which is there by virtue of its configuration. The restoring force helps in bringing back the shifted position of the superstructure close to its original position after the earthquake has passed its peak (Fig.4b). In FP systems an articulated slider (Fig.3) is allowed to move on a curved surface whenever lateral forces due to earthquake exceed the predetermined threshold of the base isolator Zayas et al. [44]; Al-Hussaini et al. [3]. Ultimately it considerably reduces the shear force on the superstructure. The damping is achieved during the movement of the articulated slider on the polished curved surface and stiffness is provided by the FP system is the function of the radius of curvature ' $R$ ' Kelly [25] of the curved surface and total weight (DL + LL) of the super structure. Friction pendulum bearings are available in "single" (Fig.3), "double" (Fig.7), "triple", and quintuple" type isolators Lee et al. [27]. Hysteresis curve and restoring force diagram are given in Fig. $4 a$ and $4 b$ respectively.

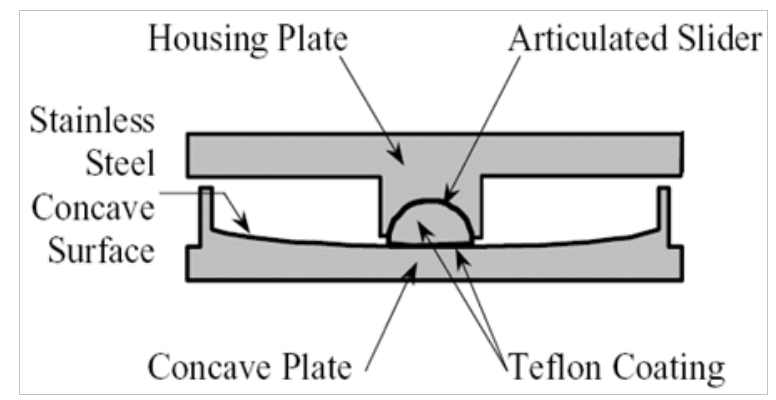

Figure 3. Cross-sectional view of a single friction pendulum bearing 


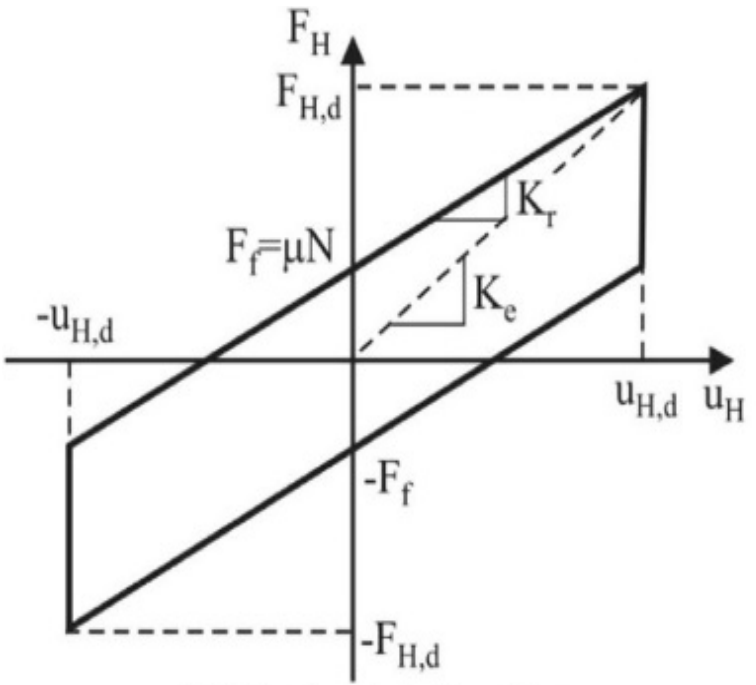

(a) Horizontal direction

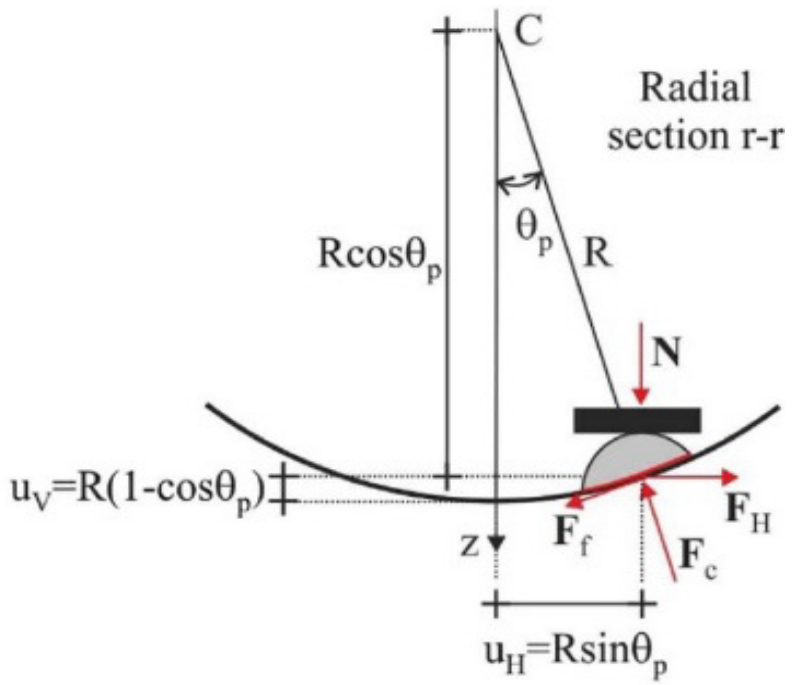

(b) Vertical plane

Figure 4. (a) Hysteretic curve of FPS and (b) Restoring force diagram

Other prominent seismic isolators are the New Zealand bearing system (NZ bearings), Pure Friction (P.F), Resilient friction base isolation (R-FBI) system, and Electric De France system (EDF).

\section{Brief Review of Research Papers}

Zayas et al. [44] discussed the construction of friction pendulum system bearings (FPS) describing in detail its features and its various components. The principle of operation of FPS and its effects on the superstructure are investigated. In this isolator, seismic isolation is obtained by shifting the natural period of isolation $\mathrm{T}$ (of rigid mass) supported on FPS to the pendulum period $T_{s}$ which is the period of a mass sliding on FPs isolators. The isolated period becomes active once the frictional force level (threshold) of the isolator is exceeded. Zayas et al. [44] concluded that in properly designed isolated structures seismic loads can be reduced by factors of 8 and greater. The elastic response spectrum which shows base shear variations concerning elastic structure period is also plotted. Zayas et al. [44] also showed that the lateral restoring stiffness is a function of vertical load and radius of curvature of the isolator. Semi spherical shape of the articulated slider is used for maintaining uniform contact pressures between the slider and the concave surface for any combination of horizontal and vertical forces generated due to earthquakes.

Briseghella et al. [7] discussed in detail various important features of friction pendulum base isolators and their use in retrofitting of existing buildings.

Three FPS models for simulation purposes have been proposed by authors who can be used for the base isolation systems.
(a) Idealized bilinear model
(b) Refined non- linear model

(c) Equivalent linear model of FPS

(a) Assumptions for idealized bi-linear models are
i). Normal force $\mathrm{W}$ is constant
ii). Displacement $(\mathrm{x})$ is constant
iii). Horizontal response is uncoupled in orthogonal directions
iv). Isolator deformations are small and planar.

Important isolator parameter's relationships are given in equations (1) to (5).

$$
\begin{aligned}
& \mathrm{F}(\mathrm{t})=(\mathrm{P} / \mathrm{R}) \boldsymbol{x}(\mathrm{t})+\mu \mathrm{P} \operatorname{Sgn}(\dot{\boldsymbol{x}}) \\
& \mathrm{F}(\mathrm{t})=\boldsymbol{K}_{\text {eff }} \cdot \boldsymbol{x}(\mathrm{t})+\boldsymbol{C}_{\boldsymbol{e f f}} \cdot \dot{\boldsymbol{x}}(\boldsymbol{t}) \\
& \text { Where } \boldsymbol{K}_{\text {eff }}=\mathrm{P} / \mathrm{R}+\mu \mathrm{P} / \boldsymbol{x} \\
& \beta_{\text {eff }}=\frac{2 \mu R}{\pi(\mu R+x)} \\
& \text { And } C_{\text {eff }}=\mathbf{2} \boldsymbol{m}_{\boldsymbol{i}} \boldsymbol{\omega}_{\text {neff }} \cdot \boldsymbol{\beta}_{\text {eff }}
\end{aligned}
$$

Where, $m_{i}$ is the mass of ith isolator, $K_{\text {eff }}$ is the effective stiffness at displacement $x, \omega_{\text {neff }}$ is effective frequency and $\beta_{\text {eff }}$ is the effective damping ratio. However, in actual practice friction is not linear but depends on relative velocity in a limited range and also depends on pressure and temperature.

Comparing the various FPS models it is found that a refined non-linear model is the most accurate model to simulate FPS bearing. On the other hand, the equivalent linear model is usually employed to make rough predictions of the seismic response of the structure. It is recommended to keep effective stiffness and displacement of the isolator to a minimum value to maintain transmitted base shear under the limit.

Braun et al. [5] discussed briefly the effect of different values of coefficient of friction in a curved surface pendulum isolator. The assembly and working principle of curved surface sliders are shown in Fig.6a and the 
hysteresis curve pattern for different loads is shown in Fig.6b. The focus has been a trade-off between dissipated energy due to frictional force and re-centering of the superstructure. The problem the authors discussed is that if dissipation of energy in friction sliding system is increased then this may be attained with higher values of friction coefficient but if we take higher values of friction coefficient in isolators it poses two serious problems i) higher threshold for movement of slider ii) Re-centering of the slider will be slow due to higher frictional force and it may stop short of the mean position and building is somewhat uplifted and slightly tilted. iii) Damping increases which increases absolute acceleration in the structure.

The dynamic friction in FPS is responsible for energy dissipation which eventually controls the re-centering capability of the structure.
Jangid [22] proposed modelling of base-isolated buildings with FP system bearings. He has stated many important assumptions in this regard which were considered by the designers of next generations in seismically protective design. The assumptions have been i). For $\mathrm{N}+1$ story building, the floors of each story of super structures are assumed to be rigid.

ii). Force deformation behavior is assumed to be linear.

iii). Friction of FP system is assumed to be independent of relative velocity at sliding surface.

iv). Restoring force provided by the FP system is considered linear.

v). The structure is excited by a single horizontal component and the effect of the vertical component is neglected.
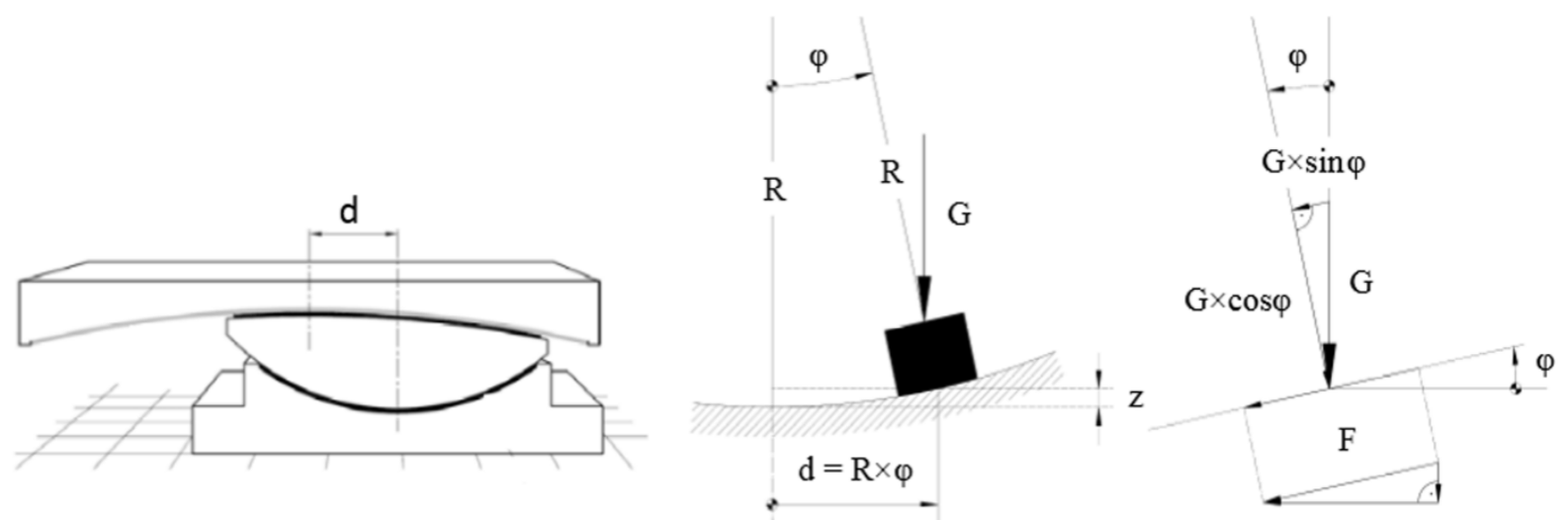

Figure 6a. Assembly and working principle of curved surface sliders Braun et al. [5]
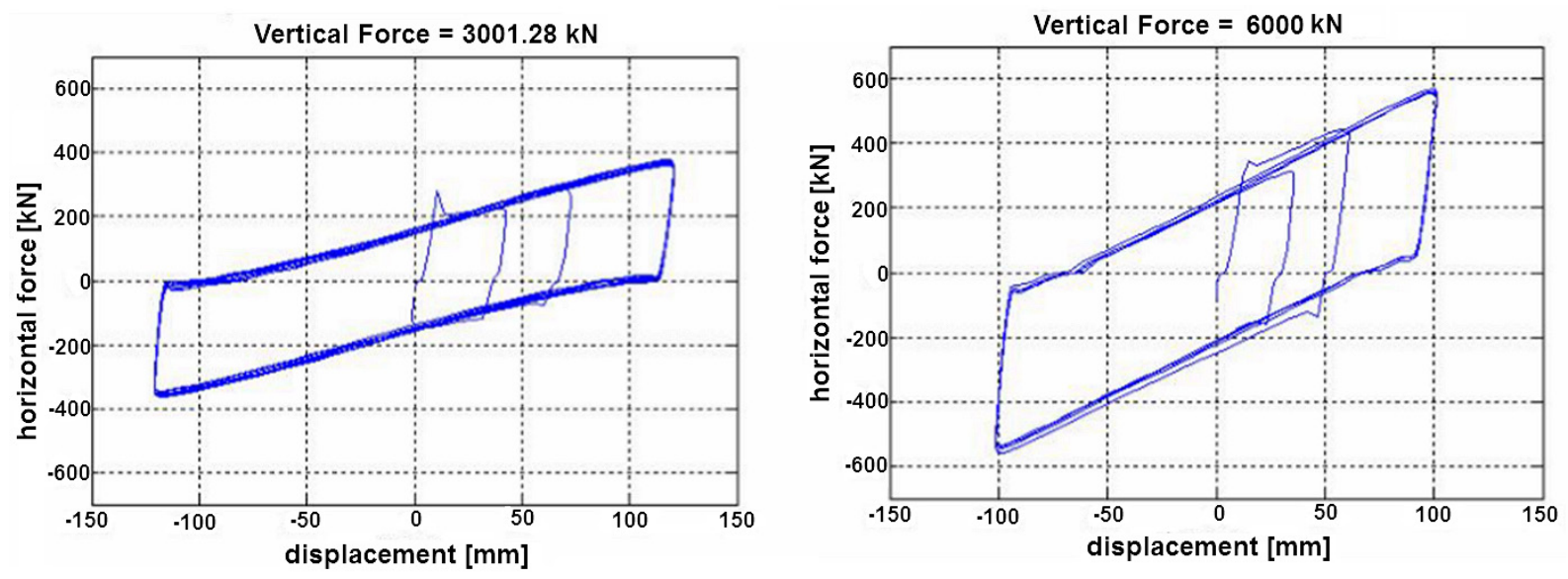

Figure 6b. Hysteresis of curved surface sliders at different loads 


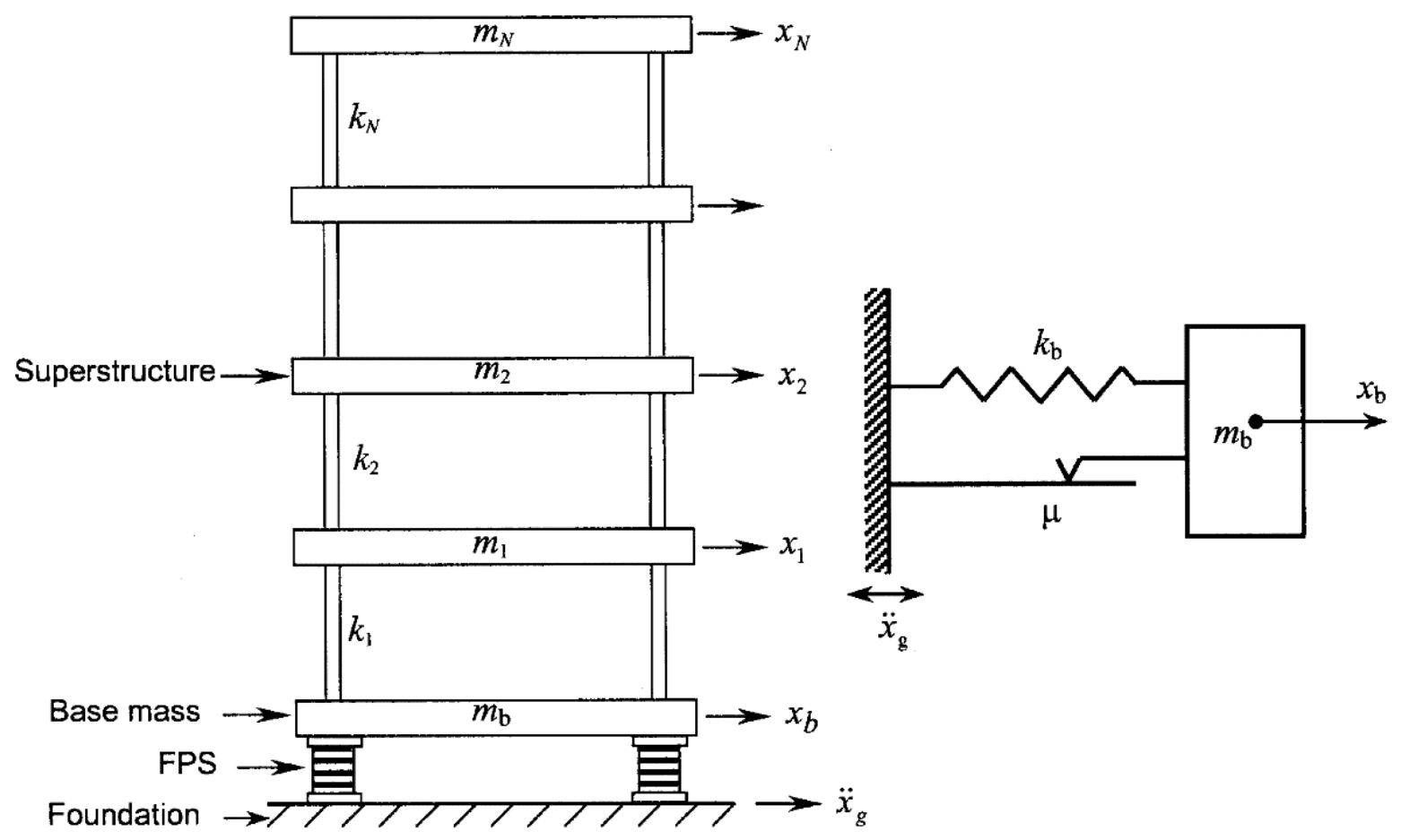

Figure 7a. Model of N-story base-isolated building and schematic diagram of the FPS Jangid [22]

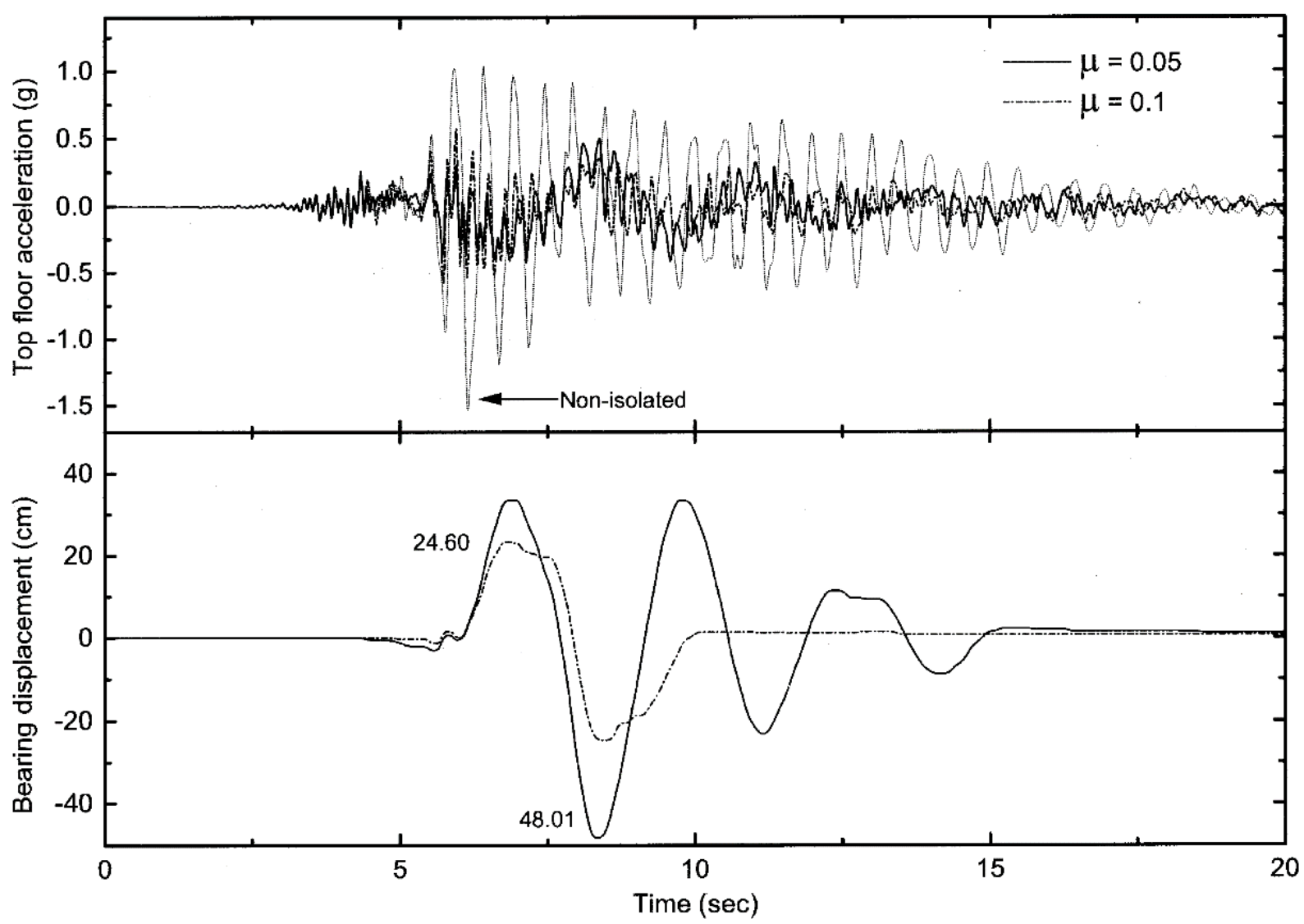

Figure 7b. Time variation of top floor absolute acceleration and bearing displacement of a five-story base-isolated structure under Imperial Valley, 1979 (Array under imperial valley earthquake motion 1979) Jangid [22]. 
Model of N-story base-isolated building and schematic diagram of the FPS and time variations of top floor absolute acceleration and bearing displacement of a five-story base-isolated structure under Imperial Valley, 1979 are shown in Fig.7a and Fig.7b respectively.

The author analyzed the seismic response of a five-story seismically base-isolated building for six recorded near-field earthquakes. It was found that there exists a certain value of friction coefficient of FPS for which top floor acceleration and isolator displacement were found to be minimum.

De Luca and Guidi [13] have discussed the evolution of the design and implementation of a base isolation system (BIS) since 1984. The authors divided the evolution into 3 stages, one from 1984-1994, second-generation from 1995-2004, and third-generation from 2005-2018. The evolution of design started from original solutions with low design vibrations periods $(\mathrm{T})$ and small displacements $(\mathrm{S})$ to the recent ones where ever-increasing parameters are targeted. The effort more recently was made to accomplish greater displacements in design to accommodate strong motions by shifting the period of the superstructure away from acceleration plateau (around $4 \mathrm{sec}$ ).

Information we receive in this paper regarding rubber-based isolators of different shapes is very useful in the design of base-isolated buildings and particularly bridges. The authors have also discussed the method to minimize the number of isolators in a particular design whereby increasing the diameter of the device and distributing the total load on the reduced no of isolators. The beneficial effects of reducing the total number of isolators in a building were also verified analytically.
Patel et al. [36] a fairly long paper took a review of base isolation systems for structures. The authors started with a brief history of base isolation starting from 1923 up to the present day. National level codes are not available for base isolation in India. Many advantages can be rightly claimed for buildings provided with base isolation. The authors Patel and Reddy have in detail discussed various types of isolation systems providing their diagrams, mechanism, and models along with a comparison of different isolator systems. A case study is conducted where the response of structures on different types of sands/gravel is considered.

It has been observed that the sand layer below the base of the structure reduces the frequency of the structure. When frequencies are reduced, the response of structure also reduces towards seismic loads. A considerable amount of energy is dissipated through movements and friction of the sand layer causing a reduction in acceleration transmitted to the structure.

$\mathrm{Su}$ et al. [41] studied the effectiveness of various base isolation schemes. The isolation systems which were the center of focus are i) laminated rubber bearings with and also without lead plug and ii) various frictional base isolation systems. However, FPS system model is not included here. The seismic loads considered were El Centro 1946 and N90W components of Mexico City 1985 earthquakes. The different base isolation systems were studied under different conditions. The results were compared and are shown in Fig.8. A new design method is evolved for FPS isolator. It was found that isolators significantly reduced acceleration transmitted to the super structure. Values of parameters used for various base isolators are given in Table 1.

Table 1. Values of parameters used for various base isolators $\mathrm{Su}$ et al. [41]

\begin{tabular}{|l|c|c|c|c|}
\hline \multicolumn{1}{|c|}{ Parameters } & Natural period To (sec) & Damping Coeff. & Friction Coeff. & Friction Coeff. \\
\hline Base isolation system & & & & \\
\hline Pure-friction (P-F) & - & - & - & 0.1 \\
\hline $\begin{array}{l}\text { Laminated rubber bearing } \\
\text { (LRB) }\end{array}$ & $2-0$ & 0.1 & 0.04 & - \\
\hline Resilient-friction (R-FBI) & $4-0$ & 0.1 & - & 0.2 \\
\hline $\begin{array}{l}\text { Electricite de France } \\
\text { (EDF) }\end{array}$ & 1.0 & 0.1 & - & - \\
\hline New Zealand & 2.0 & 0.1 & 0.04 & 0.1 \\
\hline Sliding Resilient friction & 4.0 & 0.1 & & - \\
\hline
\end{tabular}




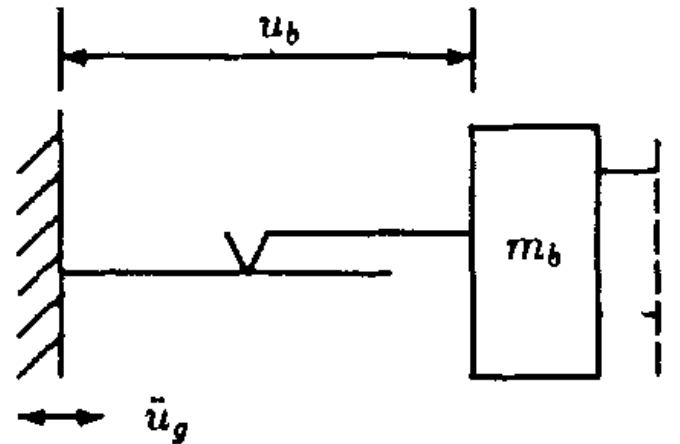

(a) P-F System

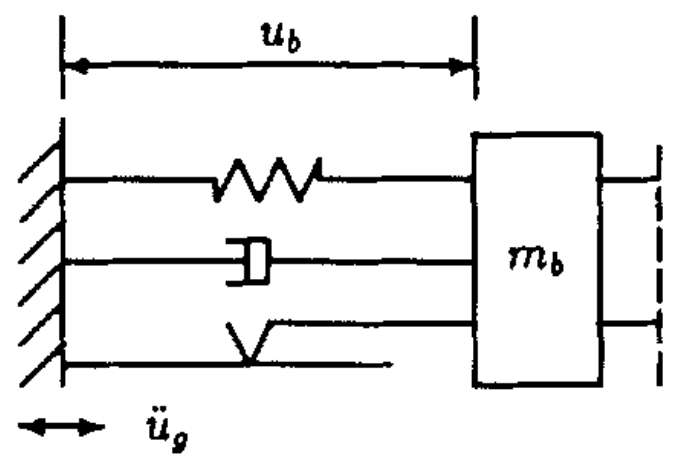

(c) R-FBI System

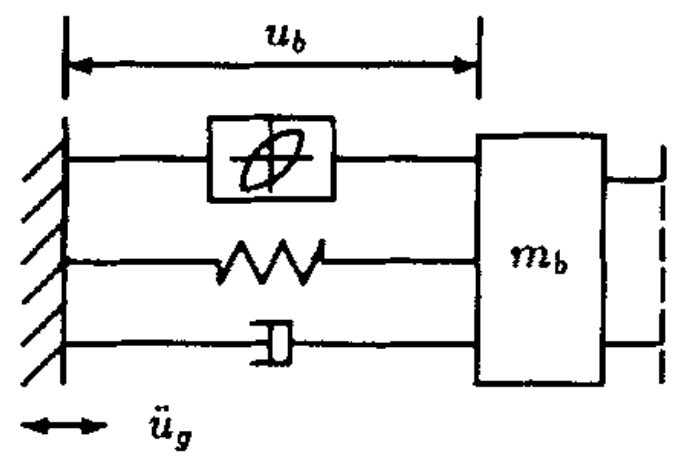

(e) NZ System

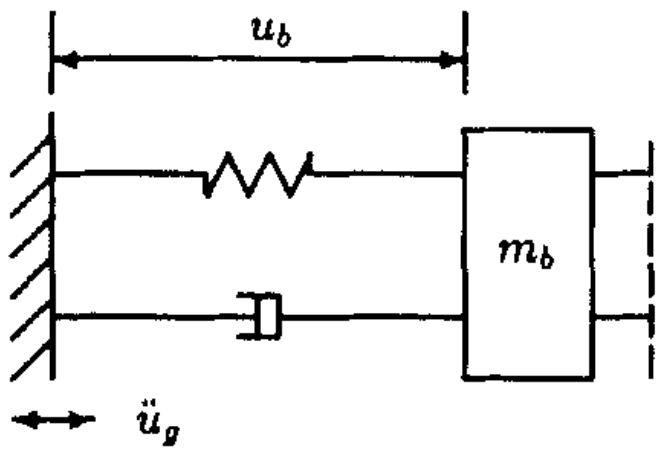

(b) LRB System
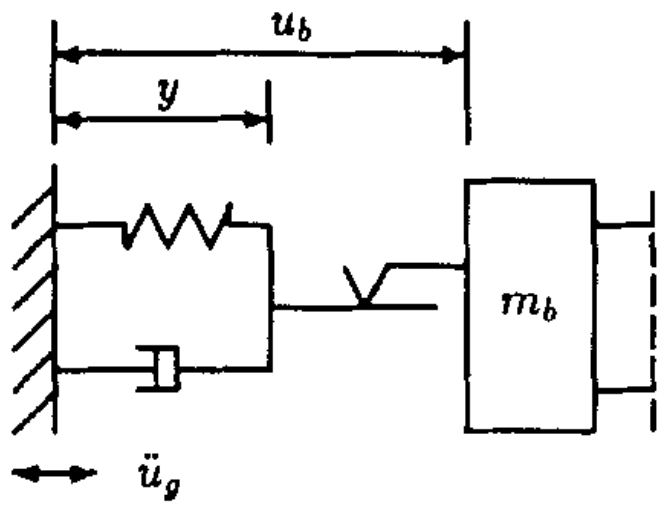

(d) EDF System
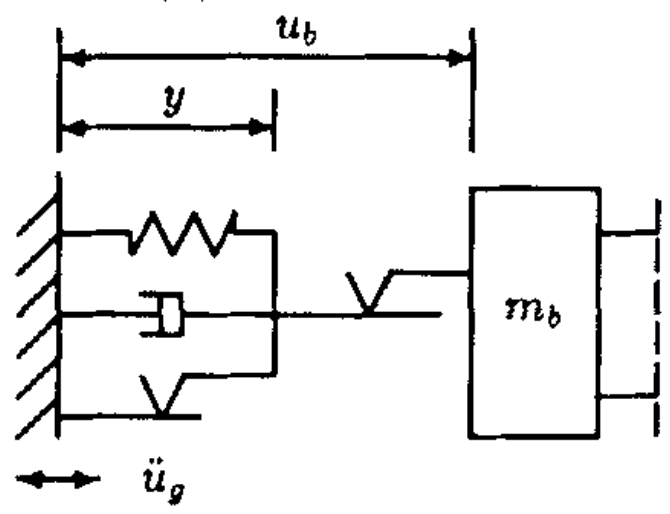

(f) SR-F System

Figure 8. Different isolation models from (a) to (f) are shown Su et al. [41]

It is observed that all the base isolators performed very well under the El Centro Earthquake of 1940. The acceleration response spectra of the structure are reduced (by the use of base isolators) by a factor of 3 to 10 when compared to the responses of a fixed-based structure. However, the results are different when the magnified El Centro earthquake is considered. Only R-FBI and SR-F performed slightly well.

Sorace et al. [40] discussed at length how multiple residential buildings constructed on the same basement using base isolators can be protected from seismic attacks.
Double friction pendulums (DFPS) are used in the design of this building due to their superior performance compared to single Friction pendulum isolation. The double friction pendulum has more choices in the same volume with two curved surfaces and an articulated double friction slider. The choice of two different radii of curvature with two different friction coefficients exists in the DFPS. Extremely enhanced performance objectives were met through the base isolation (FDE) (Frequent design Earthquake) - OP (Operational performance), SDE (serviceability design earthquake)-OP, BDE (Basic Design 
Earthquake) - ION (Immediate occupancy nonstructural), MCE (maximum considered earthquake) (-ION).

Multistory buildings with irregular plan shapes are designed. The effect of a near-fault earthquake is studied. Cost-effective design is achieved by the use of double friction pendulum isolators. Friction coefficient increases to $2.5 \%$ for velocities less than $5 \mathrm{~mm} / \mathrm{sec}$. The targeted objective in this paper was FDE-OP, SDE-OP, BDE-ION, and MCE-ION.

Narjabadifam et al. [32] studied the effect of inherent characteristics of both isolator system and superstructure on seismic performance for near as well as far-field ground motions. Base shear has been obtained for the fixed base as well as base-isolated buildings for three earthquakes i) Duzce, ii) Imperial valley, and (iii) North Ridge. It was observed that there has been a vast difference in the magnitude of shear force transmitted to the superstructure for the fixed base and base-isolated system. In base-isolated building base shear is found to be reduced by at least a factor of 3 .

i). The structure with a large mass has reduced energy input through aseismic base isolation systems.

ii). The story displacement, as well as story acceleration, are least affected by large mass structures.

iii). In general the base isolation performance is fairly good for stiffer superstructures.

Chun and Hur [11] in their landmark paper studied the isolation effect for 15 stories reinforced concrete (RC) building concerning beam-column stiffness ratio and difference in isolation period between the superstructure and an isolation layer. The study emphasizes that the isolation period should be 2.5 times more than the vibration period of the superstructure it was observed that the inter-story drift was reduced by about one-third that of non-isolated structure.

To obtain proper isolation for a proposed 15 story building the isolation period should be increased by 2.5 times of the fundamental time period of fixed-based building. Inter story drift and top story acceleration are also reduced due to (FPS) base isolation.

Jangid and Datta [23] in a comprehensive review of the design of base-isolated buildings, Jangid and Datta [23] reviewed a treasure of 95 papers from reputed scientists, engineers, and mathematicians on base isolation of single, double, and multi-story buildings. The review was divided into four major sections. In the first part, they briefly described primitive techniques used for isolation such as the construction of multi-story imperial towers in Japan in 1936 on a medium soil supported by soft soil such as mud and use of sand below the foundation or soft first story in multi-story buildings.

The review paper contains 95 papers and the findings of these papers are spread across a large area of research, therefore the reader is advised to refer to this paper for the important findings on base-isolated systems and their implementation to seismically protected buildings. The construction details, characteristics, and possible applications of different isolator bearings such as Laminated Rubber bearings (LRB), NZ- bearings, Pure Friction (P-F) bearing system, Resilient Friction Base Isolation (R-FBI) system, Electric De France (EDF) bearing system, Friction Pendulum System (FPS) bearing and High Damping Rubber Bearing (HDRB) systems were also discussed

Abd Hacheem et al. [1] described the implementation of friction pendulum bearing (FPS) as an effective base isolation system which in addition to providing effective decoupling of foundation with super structure during a seismic attack also bears re aligning property due to restoring force provided by concave surface. Abd Hacheem et al. [1] in this paper also analyzed a single friction pendulum for various values of friction coefficients over isolation characteristics. In another analysis, he has also investigated the effect of variation of radius of curvature keeping coefficient of friction constant.

Paper discussed detail various characteristics of FPS. It was concluded that base shear decreases with the increase of radius of curvature keeping the coefficient of friction constant. The effect of an increase in friction coefficient is not elaborated over base shear as the intensity of earthquake increases the isolator displacement increases. For near fault motions the isolators with higher value of friction coefficient should be designed.

Kravchuk et al. [26] presented a practical model of a single friction pendulum with four springs attached to four corners of the friction pendulum body connecting the articulated slider. They used this model to evaluate the response of two identical structures, one with base isolation and the other with no base isolation on a shaking table. The results of the experiment showed a significant decrease in lateral acceleration due to forced vibration for base-isolated structures. The authors showed that the maximum lateral acceleration for base-isolated structure during the shake table test was $0.23 \mathrm{~g}$ compared to $0.53 \mathrm{~g}$ for non-isolated structure.

Kravchuk calculated the magnitude of damping for each structure and it was observed that damping for each base-isolated structure was increased to 5 times compared with the fixed base structure. The maximum lateral acceleration for base-isolated structure during the shake table test was observed as $0.23 \mathrm{~g}$ compared to $0.53 \mathrm{~g}$ for non-isolated structure.

Dolce et al. [14] dealt in detail the frictional behavior of steel-PTFE interfaces in seismic isolators. The present manuscript is about experimental investigations on steelPTFE interfaces, aimed at estimating the effects of pressure, air temperature, state of lubrication and sliding velocity on the mechanical behavior of steel-PTFE interfaces. The first model is similar to the model proposed by Constantinou et al. [12]. In many numerical analyses where structures are equipped with steel PTFE sliding isolation, systems have been carried out by Mostaghel et al. [29] and 
Fang et al. [17]. It is assumed that friction remains constant during sliding. It is observed that actually friction does not remain constant but increases with the speed of the slider and also with the pressure on the articulated slider. The difference $\nabla$ between $\mu_{\max }$ and $\mu_{\min }$ is larger at low constant pressures, while air temperature has a negligible effect on $\nabla$ with

$$
\mu=a \cdot T^{2}-b \cdot T+C
$$

Where $\mathrm{a}, \mathrm{b}, \mathrm{c} \neq 0$

In the model proposed by Constantinou et al. [12]

$$
\boldsymbol{\mu}=\boldsymbol{\mu}_{\max -}\left(\boldsymbol{\mu}_{\max }-\boldsymbol{\mu}_{\operatorname{mim}}\right) \boldsymbol{e}^{-\alpha v}
$$

Where $\mathrm{v}$ is the velocity of slider and $\alpha$ is a constant for given pressure and temperature and condition of the interface.

The frictional force $F_{r}$ then is given by

$$
\boldsymbol{F}_{\boldsymbol{r}}=\mu . \mathrm{W} . \mathrm{Z}
$$

Where $\mathrm{W}$ is normal load and $\mathrm{Z}$ is a dimensionless hysteretic quantity.

The sliding friction coefficient is found to be the function of peak velocity and contact pressure. The sliding friction coefficient increases rapidly with the increase in velocity for a certain value beyond that it remains constant. The difference between maximum and minimum values of the sliding friction coefficient is large at low values of contact pressure. Lubrication in steel PTFE reduces the frictional resistance by a factor of 5-8. Throughout the manuscript, there is no mention that how isolation capability is increased using PTFE.

Panchal et al. [35] discussed the origin of a variable friction pendulum bearing. The need arose because simple friction pendulum bearing systems were unable to handle large pulse-type motions which used to hit the superstructures near-fault locations, the response of FPS was not appropriate under near-fault ground motion which consisted of long-period pulse type of motions. It was duly observed that as the friction coefficient of FPS increased the acceleration of base-isolated building also increased. The same phenomena repeated with the shear force. It is obvious that for near-fault earthquakes the isolator displacement will be large and so will be the size of the isolator. The large size and volume of the isolator will cost more and the cost of commissioning will also be high.

The variable friction pendulum system (VFPS) isolator was suggested as a cheap remedy for this problem which proved to be very successful. By using variable friction pendulum bearing the floor displacement and top floor acceleration was conveniently controlled. The friction coefficient $\mu$ of variable pendulum isolator was given in the paper as

$$
\boldsymbol{\mu}=\left(\mu_{0}+a_{1}\left|x_{b}\right|\right) e^{a_{2} x_{b}}
$$

Where $a_{1}$ and $a_{2}$ are constants, $\mu_{0}$ is the initial value of the coefficient of friction $\mu$ and $x_{b}$ is the displacement of the isolator. The initial stiffness of isolator $\mathrm{K}_{\mathrm{i}}$ is given as

$$
K_{i}=\frac{\mu_{\max } \cdot W}{x_{\text {bmax }}}
$$

Where $x_{b \max }$ is given by, $\quad \boldsymbol{x}_{\boldsymbol{b m a x}}=\frac{\boldsymbol{a}_{1}-\mu_{0} a_{2}}{\boldsymbol{a}_{1} a_{2}}$

and the period of VFPS is given by $T_{i}$

$$
T_{i}=2 \pi \sqrt{\frac{M}{K_{i}}}
$$

where $\mathrm{M}$ is the mass of the superstructure.

i). With VFPS installed, the displacement of isolator and base shear for near-fault ground motions can be easily controlled.

ii). While using VFPS as a base isolator for near-fault earthquake vibrations it is observed that there is an optimum initial period for which displacement of isolator and base shear is the minimum. The optimum $T_{i}$ is found near $1.5 \mathrm{sec}$.

iii). If the number of stories of the superstructure is increased in a VFPS isolated building then it is observed that top floor acceleration is increased.

iv). Isolator displacement increases with an increase in the isolation period.

v). For cycloidal excursions, the displacement of isolator and base shear in VFPS are found to be remarkably lower compared to FPS but for both isolators top floor acceleration remains almost the same.

Cardone et al. [9] an exhaustive paper discussed the problem of re-centering the isolated structure when subjected to the earthquake ground motion. This is the main problem that has been taken up by only a few researchers. In base isolation, restoration of the structure after the earthquake has passed is a major concern. In friction pendulum systems restoring force is proportional to $\mathrm{W} / \mathrm{R}$ where $\mathrm{W}$ is the total weight of the building and $\mathrm{R}$ is the radius of curvature of the curved surface as shown in Fig.9. When the articulated slider does not return to its initial position at the end of the earthquake it leaves the whole of the superstructure in a slightly tilted and uplifted position. This permanent shift may affect the functionality of the structure. 


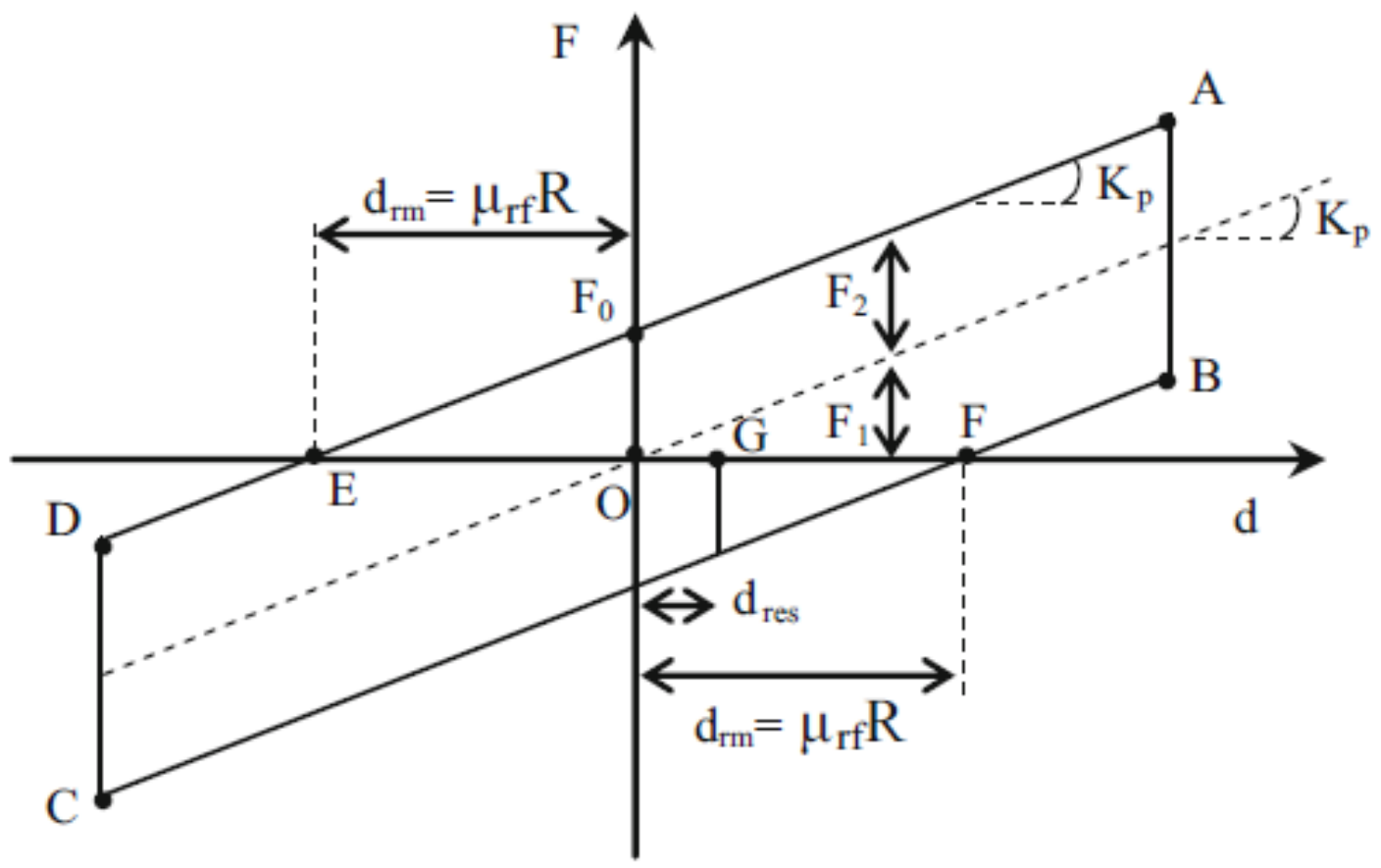

Figure 9. Restoring capability of FPS isolators Cardone et al. [9]

i). The parameter $\left(\mathrm{d}_{\max } / \mathrm{d}_{\mathrm{rm}}\right)$ affects the recentering capability of FPS. Where $d_{\max }$ is defined as the maximum displacement of FPS caused by earthquake and $d_{r m}$ is maximum residual displacement. $d_{r m}$ is also depicted as

$$
d_{r m}=\mu_{\text {slow }} . R
$$

where $\mu_{\text {slow }}$ is the dynamic friction coefficient of FPS and R is the radius of curvature of the curved surface of FPS.

ii). The re-centering or restoring capability of FPS depends on the value of $\mathrm{d}_{\max }$ and at the same time, it also depends on the characteristics of the earthquake.

iii).

If the ratio:

$$
\left(d_{\max } / d_{r m}\right)>2.5
$$

then it implies that residual displacements are negligible and re-centering capability of FPS is good.

iv). The residual displacement in general of FPS can be given by

$$
d_{\text {res }}\left(90^{\text {th }}\right)=0.18\left(d_{\max } \cdot d_{r m}\right)^{1 / 2}
$$

where $90^{\text {th }}$ represents the $90^{\text {th }}$ percentile of observed data.

v). The residual displacement may accumulate due to main-shock and after-shocks but it may never be greater than $\mathrm{d}_{\mathrm{rm}}$.

Kelly [25] a research paper discussed the role of damping in seismic isolators. In the event of high-intensity ground motions, it is observed that pulse type of ground motions is generated at near-fault locations. These types of ground motions create large displacements in the superstructure. To reduce the effect of large intensity ground motions due to near-fault locations of the earthquake the technique which has been suggested by seismologists is the use of supplementary dampers. These dampers are useful as far as reduction of displacement is concerned but increasing damping of isolators increases inter-story drift and floor accelerations of the superstructure.

Supplementary dampers are used to reduce the effects of large intensity ground motions. The reduction in displacement is observed due to the implementation of dampers but at the same time, top floor acceleration and inter-story drift increases in base-isolated structures.

Felix Weber et al. [16] A landmark paper discussed isolation performance and adaptive behavior of triple friction Pendulum. The paper investigates the isolation performance of the given pendulum bearing as a function of peak ground accelerations. It has initially described the sliding regimes in five regions of interest to understand the function of the triple friction pendulum. Sliding regime I: relative motion only occurs on sliding surfaces 2 and 3 with equal radii and friction coefficients. Sliding regime II: relative motion occurs on surfaces 1,2 , and 3 . the resulting friction coefficient is $\mu_{\text {equiv }}$ which can be interpreted as an "average" friction coefficient is, therefore, greater than $\mu_{2}=\mu_{3}$ but less than $\mu_{1}$.

$$
\left(\boldsymbol{R}_{e f f, 1}+\boldsymbol{R}_{e f f, 2}+\boldsymbol{R}_{e f f, 3}\right)^{-1}
$$

and all surfaces 1 to 4 with slope

$$
\left(\boldsymbol{R}_{e f f, 1}+\boldsymbol{R}_{e f f, 2}+\boldsymbol{R}_{e f f, 3}+\boldsymbol{R}_{e f f, 4}\right)^{-1}
$$

$\mu_{\text {equiv }}$ turns out to be significantly smaller than $\mu_{4}$ because the entire sliding motion is split into simultaneous sliding on surfaces 1, 2, and 3 and 
simultaneous sliding on all surfaces 1 to 4 . Therefore

$K_{\text {equiv }}$ lies between

$$
\begin{gathered}
\mathrm{W} /\left(\boldsymbol{R}_{\boldsymbol{e f f}, \mathbf{1}}+\boldsymbol{R}_{\boldsymbol{e f f}, \mathbf{2}}+\boldsymbol{R}_{\boldsymbol{e f f}, \mathbf{3}}\right) \text { and } \\
\mathrm{W} /\left(\boldsymbol{R}_{\boldsymbol{e f f}, \mathbf{1}}+\boldsymbol{R}_{\boldsymbol{e f f}, \mathbf{2}}+\boldsymbol{R}_{\boldsymbol{e f f , 3}}+\boldsymbol{R}_{\boldsymbol{e f f}, \mathbf{4}}\right)
\end{gathered}
$$

Sliding regime IV: sliding on surface 1 is stopped by its restrainer which evokes a stiffening effect in the force-displacement trajectory. Since simultaneous sliding on surfaces 1 and 4 dominates the force-displacement trajectory of sliding regime IV, $\mu_{\text {equiv }}$ increases within sliding regime IV towards $\mu_{4}$. Sliding regime V: sliding on surfaces 1 and 4 is stopped by their restrainers while sliding continuously on sliding surfaces 2 and 3 . This evokes the stiffening behavior at very small friction. As a result, $K_{\text {equiv }}$ increases while $\mu_{\text {equiv }}$ decreases in sliding regime $\mathrm{V}$.

Shows that the triple friction pendulum: a) performs better at small peak ground accelerations due to the low friction of the articulated slider assembly that is actuated by relative motion in the bearing even at very low shaking level, b) generates slightly worse isolation when sliding regimes II to IV are activated, and c) evokes a strongly deteriorated isolation when sliding regime $\mathrm{V}$ is triggered due to its increased stiffness and reduced friction properties. As compared to the conventional non- adaptive double FP with same curvature.

In this paper, Mazza et al. [30] have studied torsion and residual displacement and uplift of the friction pendulum (FP) system for base-isolated structures located in near-fault areas. The investigation is carried out to examine two effects in FP bearing: i) friction variability as a function of sliding velocity and ii) frictional force and restoring stiffness during sliding with axial load variations. Torsional effects and residual displacements were studied for unscaled powerful earthquakes.

Unscaled earthquakes with prominent horizontal components produce torsional effects which need to be handled in the design. Unscaled earthquakes with prominent vertical components are responsible for significant residual displacements in FP base-isolated structures. It is further noted that with the increase of radius of curvature residual displacement decreases. Mean floor rotation is found on the top floor of the building.

Mithranjali et al. [31] have presented the finite element modeling of friction pendulum system for (different radii) of a multistory building subjected to earthquake force, by using V18 software. In this paper, G+12 Story building is used as a model. EL Centro earthquake is used for time history analysis.

The results obtained from the analysis showed the reduction in base shear, net displacement, and increase in the period of the building when the radius of curvature is increased.

Matsagar et al. [28] This paper investigated the influence of isolator's characteristics on the seismic response of multistory buildings with base isolation. The isolators were modeled using bilinear hysteretic and equivalent linear elastic behavior. The above two models were discussed in detail in this paper. The seismic response of a multi-story base-isolated building is investigated under various real earthquake ground motions for bi-linear and equivalent linear isolator characteristics. In the analysis, Matsagar [28] have applied Newmark's step-by-step method Hilber et al. [19].

The variations of top floor absolute acceleration and bearing displacement were recorded. It was also observed that there is a significant difference in top floor acceleration between rigid and flexible superstructures when $T_{s}=0$ (rigid and when $T_{s}>0$ ). However, bearing displacement was not much influenced by the increase in superstructure flexibility. The response of the base-isolated structure is also fairly influenced by the shape of the hysteresis loop of the isolator.

Dia Eddin et al. [33] presented a paper on seismic base isolation in reinforced concrete structures using a rubber-based isolator. To verify the effect of the base isolation system on concrete structures two different structures are analyzed using SAP 2000. The first structure which was analyzed in this paper was a five-story regular structure. The second structure which was analyzed was an irregular RC structure of 5 stories. The HDR (high damping rubber) bearings were used for isolation in both buildings. Non-linear time history analysis was carried out employing SAP software. Time histories were taken from El Centro, Loma, and coyote earthquakes.

There are reductions in base shear in $\mathrm{X}$ and $\mathrm{Y}$ directions as $74.5 \%$ and $76.65 \%$ for symmetric plan building when base-isolated building results are compared with fixed-based building shear force results. For non-symmetric plan building these values are slightly reduced i.e, $72 \%$ and $73.17 \%$ respectively. The base moment in $\mathrm{X}$ - and $\mathrm{Y}$ directions for the base-isolated structure is less than the moment for the fixed base condition. The reduction in inter-story drift ratio is $76.67 \%$ in symmetric plan building as compared to $50 \%$ in non-symmetric plan building. Top floor acceleration, turning over moments, and rotations in floors are not evaluated by the authors.

In a short paper, Rincy [37] discussed the role of viscous dampers and friction dampers for the protection of $\mathrm{RC}$ framed buildings from seismic loads. Pushover analysis is used in this paper for analysis. The response of building such as story drift, displacement, and period performance for the fixed base and the base-isolated building is studied. The paper deals with the performance of RC structures with rubber pads isolation systems. The $\mathrm{G}+3$ and $\mathrm{G}+9$ buildings using SAP 2000, in an exhaustive study have shown the performance of isolation systems on floor accelerations, joint displacements, inter-story drifts, and base shear of the building.

The behavior of the building structure resting on friction isolators and rubber bearing was compared with a fixed base structure under maximum capable earthquake (MCE). The results were satisfactory. 
Jangid et al. [24] discussed various parameters of base-isolated structures situated near-fault locations. Six pairs consisting of parallel and normal directions w.r.t fault sites were considered and an average response spectrum was obtained. The study in this paper showed that these motions consisted of significant energy at high frequencies Other components of near-fault motions were long-period pulses. The effect of isolation damping was also studied on various isolation systems under near-fault motion.

It was observed that there was a certain value of isolator damping for which the building acceleration was found to be minimum.

Bhagat et al. [4] presented a study where base-isolated reinforced buildings with various isolation systems under near-fault and far fault motions are investigated. The aging effect of base isolators was also taken into account. Results of the base-isolated building were compared with fixed-based counterparts. Base shear coefficient with roof drift ratio was plotted for 4-story, 8-story, and 12- story buildings.

The results of the analysis indicated no structural damage under DE-level motions for near-fault and far fault motions and $\mathrm{MCE}_{\mathrm{R}}$ level near-fault motions. Significant reduction of superstructure response of 12 stories base-isolated building compared to the fixed base condition indicated that base isolation is very successful in taller buildings.

Sharma et al. [39] discussed the stiffness developed in the beam and column joints when RC framed structures are subjected to actual seismic loads. Effects of lateral seismic loading on frames are observed by authors and reported in this paper. The horizontal shear, vertical shear, and principal tensile stiffness are calculated. Seismic retrofitting strategies for $\mathrm{RC}$ beam-column joints were also studied in detail in the paper.

It was shown that concrete jacketing was a good option to strengthen the frame members. Code recommendations such as IS 13935: 1993(2002) were discussed in detail. Fiber-reinforced polymers FRP were also used in seismic retrofitting of RC structures and their main benefits were: i) very high specific strength and ii) high corrosion resistance.

Cardone et al. [10] discussed a very popular scheme called displacement-based design using different types of isolation systems where we are interested in friction pendulum-based design. The main point in the proposed method is the target displacement profile for structure. This method is suitable where performance-based design is intended. This method can discretely give performance levels such as IO, LS, CP, and C.

Also, the proposed design is developed for base isolation systems. The different base isolation systems selected were a) Friction Pendulum systems (FPS) bearings, b) high damping Rubber Bearings (HDRB), c) lead rubber bearings (LRB), and various damping and position restoring devices. Non-linear time history analysis is carried out to assess the accuracy of this technique.
This is a long paper containing a large number of findings regarding direct displacement-based design (DDBD) which cannot be included in the body of this paper. However, the important finding of this paper is shared as follows: Results of DDBD analysis are checked by Non-linear time history analysis and are found to be conveniently accurate with a rider that some minor modifications in DDBD are required.

Buckle [8] has described various schemes of passive control of structures to improve their performance during seismic attacks. Passive control systems include seismic base isolation systems, tuned mass dampers, and mechanical energy dissipaters. These are called passive control devices as they do not require any energy source. At the end of this paper, the author discussed design aids, guidelines, specifications, and Codes.

The limitations of these passive control devices are

i). Doubtful behavior regarding their response i.e., they are unlikely able to produce the appropriate response required to protect the building from ground motions emanating from the far-field as well as near field faults.

ii). It may not show the optimal response for large as well as small seismic attacks.

iii). If the earthquake is of considerably large magnitude then it is not certain that appropriate limit states will be achieved.

Nguyen et al. [34] proposed a scheme to design a 2D model of 5 story Building subjected to earthquakes in Vietnam using single friction pendulum isolators. The model is analyzed for two cases one for the fixed base and the other for an isolated building. Whenever acceleration data are chosen then it is immediately using software that converts it to new values which suit the local conditions and are also acknowledged by the local code provisions. The author discussed the design procedure in the paper proposing various forces in a single FPS presenting its model. They also defined the stiffness of a single FPS and its period. A complete 2D model with seismic isolated structure with single FPS type isolators is proposed.

Absolute acceleration for fixed-base buildings increases almost linearly from the first floor to the fifth floor while it approximately remains constant for FPS base-isolated 5 story buildings. Inter story drift is almost constant through the number of floors for the FPS base-isolated 5 story building while it has a large initial value for the fixed-base building where it increases initially from the first floor, remains constant, and then decreases slightly as it approaches the top floor.

Ikago et al. [20] A conference paper proposed a design strategy which deals with the problem of excessive displacements in high-rise and seismically isolated buildings.

The authors have observed that to control excessive displacements in long period structures subjected to long-duration ground motions if some damping devices are added to suppress excessive displacements it may increase 
corresponding shear forces and floor response accelerations. To solve this problem rate-independent dampers are used. This application reduces displacement in a long period of building structures without increasing shear forces and floor accelerations.

Fujii et al. [18] have discussed at length various aspects of seismically isolated buildings such as the benefits of using base isolation. The authors emphasized the various benefits of using base isolation such as reduction of acceleration response of floors concerning non-structural elements. The authors also explained other benefits such as that the most gravity-load-carrying members remain elastic and minor damage to non-structural elements is observed. Fujii et al. [18] main focus in the paper was to propose a procedure to predict the force demand in superstructure members of the base-isolated buildings using the pushover analysis.

The method is based on evaluating the contribution of the first and higher modes to peak response. Also, the base-isolated systems increase the period of the superstructure which protects the building from major damages. The author's main focus was to propose a procedure to predict the force demand in super structure's members of base-isolated buildings using the pushover analysis. The second modal response better predicts the maximum floor acceleration and maximum shear forces of the vertical members in the superstructure.
Downey et al. [15] proposed a new Passive Variable Friction Pendulum Damper (PVFD) for increasing structural resistance to multi-hazard excitations. The PVFD as it is called is found to be capable of mitigating different hazards from wind and ground motions. In the event of wind pressure, device performance is fairly satisfactory and in the event of an earthquake, the device effectively reduces the building inter-story drift to maintain strength-based motion requirements. Other passive control devices which have been employed in the protection of the buildings from seismic attacks are visco-elastic fluid dampers, base-isolation systems, and friction dampers including linear and rotational configurations.

A reduction in absolute acceleration is noticed on all the floors of a simulated three-story building. Most benefited was the top floor due to the installation of PVFD. With respect to inter-story drift first floor observed the maximum reduction due to this scheme. The main disadvantage of passive devices is that they operate over a limited bandwidth and can mitigate the single type of excitations. A comparison of different base-isolated systems with FD and PVFD installed base-isolated systems would have been a good addition to this paper.

A brief table 2 has been constructed below to compare the above work and also find similarities among the findings in the tabular form, for the reader to understand this work more conveniently.

Table 2. Comparison about findings and similarities

\begin{tabular}{|c|c|c|c|c|}
\hline S.no. & Paper Authors & Year & Findings & $\begin{array}{l}\text { Similarities } \\
\text { (paper } \\
\text { reference no.) }\end{array}$ \\
\hline 1. & $\begin{array}{l}\text { Muthranjali et } \\
\text { al. [3] }\end{array}$ & 2021 & $\begin{array}{l}\text { They showed that from analysis the reduction in base shear, net displacement } \\
\text { and increase in the period of the building when the radius of curvature is } \\
\text { increased using FEM analysis. }\end{array}$ & [1] \\
\hline 2. & $\begin{array}{l}\text { Abd- Hasheem } \\
\text { et al. [1] }\end{array}$ & 2021 & $\begin{array}{l}\text { It was concluded that the base shear decreases with the increase of radius of } \\
\text { curvature keeping the coefficient of friction constant. }\end{array}$ & [3] \\
\hline 3. & $\begin{array}{l}\text { Matsagar et al. } \\
\text { [28] }\end{array}$ & 2021 & $\begin{array}{l}\text { The response of the base isolated structure is also fairly influenced by the shape } \\
\text { of the hysteresis loop of the isolator. }\end{array}$ & [7] \\
\hline 4. & $\begin{array}{l}\text { Jangid et al. } \\
{[24]}\end{array}$ & 2021 & $\begin{array}{l}\text { It was observed that there was a certain value of isolator damping for which the } \\
\text { building acceleration was found to be minimum. }\end{array}$ & [26] \\
\hline 5. & $\begin{array}{l}\text { Nguyen et al. } \\
{[34]}\end{array}$ & 2021 & $\begin{array}{l}\text { Absolute acceleration for fixed base building increases almost linearly from the } \\
\text { first floor to the fifth floor while it is approximately remains constant for FPS } \\
\text { base isolated } 5 \text { story binding. }\end{array}$ & \\
\hline 6. & Fuji et al. [18] & 2020 & $\begin{array}{l}\text { The author's main focus was to propose a procedure to predict the force demand } \\
\text { in super-structures member of base isolated buildings using the pushover } \\
\text { analysis. }\end{array}$ & [10] \\
\hline 7. & $\begin{array}{l}\text { De Luca et al. } \\
{[13]}\end{array}$ & 2019 & $\begin{array}{l}\text { The author has discussed the method to minimize the number of isolators in a } \\
\text { particular design whereby increasing the diameter of the device and distributing } \\
\text { the total load on the reduced number of isolators. }\end{array}$ & \\
\hline 8. & $\begin{array}{l}\text { Narjabadifam et } \\
\text { al. [32] }\end{array}$ & 2019 & $\begin{array}{l}\text { FPS isolation reduces the energy input to the superstructure more than as seen in } \\
\text { HRB for near field and far field ground motions. }\end{array}$ & [9], [5] \\
\hline 9. & $\begin{array}{l}\text { Dia-Eddin et al. } \\
\text { [33] }\end{array}$ & 2019 & $\begin{array}{l}\text { They carried out analysis of symmetric and plan irregular building and had } \\
\text { obtained that the Structure with plan irregularities in the } \mathrm{x} \text { and y direction have } \\
\text { less base shear, overturning moment and inter-story drift as compared to the } \\
\text { symmetric building. }\end{array}$ & [40] \\
\hline 10. & $\begin{array}{l}\text { Downey et al. } \\
{[15]}\end{array}$ & 2018 & $\begin{array}{l}\text { The reduction in absolute acceleration is noticed on all the floors of a simulated } \\
\text { three story building. Most benefited is the top floor due to the installation of } \\
\text { PVFD. }\end{array}$ & \\
\hline
\end{tabular}


Table 2. Continued

\begin{tabular}{|c|c|c|c|c|}
\hline 11. & Bhagat et al. [4] & 2017 & $\begin{array}{l}\text { Base isolation significantly improves the superstructure performance } \\
\text { when compared to a fixed base condition even for a flexible } 12 \text { story } \\
\text { building. }\end{array}$ & \\
\hline 12. & Ikago et al. [20] & 2017 & $\begin{array}{l}\text { The authors have observed that, to control excessive displacements in } \\
\text { long period structures subjected to long - duration ground motions is } \\
\text { some damping devices. }\end{array}$ & [37] \\
\hline 13. & $\begin{array}{l}\text { Felix Weber et al. } \\
{[16]}\end{array}$ & 2017 & $\begin{array}{l}\text { Shows that the triple friction pendulum performs better at small peak } \\
\text { ground accelerations due to the low friction of the articulated slider } \\
\text { assembly that is actuated by relative motion in the bearing even at very } \\
\text { low shaking level, As compared to the conventional non- adaptive double } \\
\text { FP with same curvature. }\end{array}$ & \\
\hline 14. & Mazza et al. [30] & 2016 & $\begin{array}{l}\text { The unscaled earthquakes with prominent horizontal component produce } \\
\text { torsional effects which needed to be handled in design. }\end{array}$ & \\
\hline 15. & Cardone et al. [9] & 2015 & The author has discussed the problem of re-centring the isolated structure. & [5] \\
\hline 16. & Chun et al. [11] & 2015 & $\begin{array}{l}\text { To obtain proper isolation for a high rise building the isolation period } \\
\text { should be increased by } 2.5 \mathrm{sec} \text { times of the fundamental time period of the } \\
\text { fixed based building. }\end{array}$ & \\
\hline 17. & Sorace et al. [40] & 2014 & $\begin{array}{l}\text { For multi-storeyed buildings with plan irregularities and with near fault } \\
\text { ground excitation. The double friction pendulum isolator is proved to be } \\
\text { cost effective design. }\end{array}$ & [33] \\
\hline 18. & Brighella et al. [7] & 2013 & $\begin{array}{l}\text { Comparing the various FPS models, it is found that a refined non-linear } \\
\text { model is the most accurate model to simulate FPS bearing. }\end{array}$ & [28] \\
\hline 19. & Patel et al. [36] & 2013 & $\begin{array}{l}\text { The author has observed that the sand layer below the base of the } \\
\text { structure reduces the frequency of the structure. }\end{array}$ & \\
\hline 20. & Rincy [37] & 2012 & $\begin{array}{l}\text { Structure with isolators and damping devices perform good during } \\
\text { seismic loading. The isolated structure has reduced story drift and story } \\
\text { displacement. }\end{array}$ & [20] \\
\hline 21. & Sharma et al. [39] & 2011 & $\begin{array}{l}\text { It was shown that concrete jacketing is a good option to strengthen the } \\
\text { frame members. Fibre-reinforced polymers FRP were also used in } \\
\text { seismic retrofitting of RC structures and their main benefits were very } \\
\text { high specific strength and high corrosion resistance. }\end{array}$ & \\
\hline 22. & Braun et al. [5] & 2010 & $\begin{array}{l}\text { The dynamic friction in FPS is responsible for energy dissipation which } \\
\text { eventually controls the re-centring capability of the structure. }\end{array}$ & [9], [32] \\
\hline 23. & $\begin{array}{l}\text { Cardone et al. } \\
{[10]}\end{array}$ & 2010 & $\begin{array}{l}\text { In this paper the author has proposed the direct displacement feared } \\
\text { design (DDBD) method for different five types of isolation system and } \\
\text { then compared the responses from non-linear time history analysis NTHA } \\
\text { as force based analysis procedure and obtained that the results are } \\
\text { satisfactory. }\end{array}$ & [18] \\
\hline 24. & $\begin{array}{l}\text { Kravchuk et al. } \\
{[26]}\end{array}$ & 2008 & $\begin{array}{l}\text { The author calculated the magnitude of damping for each structure and it } \\
\text { was observed that damping for each base isolated structure was increased } \\
\text { to } 5 \text { times compared with the fixed base structure. }\end{array}$ & [24] \\
\hline 25 . & Panchal et al. [35] & 2008 & The author has introduced a new type of FPS isolator known as VFPS. & \\
\hline 26. & Jangid [22] & 2005 & $\begin{array}{l}\text { The author analysed the seismic response of a five story seismically base } \\
\text { isolated building for six recorded near field earthquakes. It was found that } \\
\text { there exist a certain value of friction coefficient of FPS for which top } \\
\text { floor acceleration and isolator displacement were found to be minimum. }\end{array}$ & \\
\hline 27. & Dolce et al. [14] & 2005 & $\begin{array}{l}\text { In FPS the sliding friction coefficient is found to be the function of peak } \\
\text { velocity and contact pressure. }\end{array}$ & \\
\hline 28. & Buckle et al. [8] & 2000 & $\begin{array}{l}\text { The limitations of passive control devices are doubtful behaviour } \\
\text { regarding their response i.e. they are unlikely able to produce the } \\
\text { appropriate response required to protect the building from ground } \\
\text { motions emanating from the fan-field as well as near-field faults. }\end{array}$ & \\
\hline 29. & Kelly et al. [25] & 1999 & $\begin{array}{l}\text { The author has used supplementary dampers to reduce the effects of large } \\
\text { intensity ground motions. }\end{array}$ & [8], [24], [26] \\
\hline 30. & $\begin{array}{l}\text { Jangid and Datta } \\
{[23]}\end{array}$ & 1995 & $\begin{array}{l}\text { In this paper, possible applications of different isolator bearing such as } \\
\text { LRB, NZ- bearing, (P-F) bearing system, (R-FBI) system, EDF bearing } \\
\text { system FPS and HDRB systems were discussed }\end{array}$ & $\begin{array}{l}{[3,1,7,34,32} \\
9,11,7,5,10 \\
35,14]\end{array}$ \\
\hline 31. & Zayas [44] & 1990 & $\begin{array}{l}\text { Showed that the lateral restoring stiffness is a function of vertical load } \\
\text { and radius of curvature of the isolator. }\end{array}$ & {$[3],[1]$} \\
\hline 32. & Su et al. [41] & 1989 & $\begin{array}{l}\text { The acceleration response spectra of the structure are reduced by the use } \\
\text { of base isolator by a factor of } 3 \text { to } 10 \text { when compared to the fixed based } \\
\text { structure to the isolated structure. The R-FBI and SR-F performed } \\
\text { slightly well. }\end{array}$ & [23] \\
\hline
\end{tabular}




\section{Conclusions}

In view of present extensive literature review work for seismically isolated structures especially for friction pendulum system FPS all the above researchers have contributed to the best of their efforts and should be acknowledged, but among them three research works perhaps seem to be novel so far, they are.

1. Seismic Behaviour of Base-isolated Buildings Jangid and Datta [23]

2. DDBD method of analysis for isolated structures in comparison to NTHA Cardone et al [10].

3. Re-centring capabilities of FPS isolation Cardone et al [9].

\section{Scope of Future Work}

i). To investigate performance criteria of foundations based on over-turning effect and/or soil-structure interaction.

ii). To evolve less complex methods and less time-consuming methods for non-linear dynamic analysis concerning available software.

iii). To find out new more accurate iteration methods for implicit time integration.

iv). To find out seismic isolation techniques that can take care of vertical accelerations and vertical deformations in the structures more accurately during seismic attacks.

v). To study the aging effects of base isolators on the seismic response of different types of structures.

vi). Without compromising seismic safety, the study is needed to bring out new techniques to reduce the number of base isolators used in a given building.

vii). Reliability study of semi-active and active dampers used to mitigate seismic hazards.

viii). Considerable scope on doing research on experimental models, as very few or even none have conducted experimentation on FPS isolation specially for reinforced concrete building frames using FPS isolation.

ix). Compare responses using different isolation devices by experimental modelling of reinforced concrete building frames is also a future scope in this field.

\section{REFERENCES}

[1] Z. A. Hacheem, A. L. I. K AL-Shimmari, "Finite element analysis of a friction pendulum bearing base isolation system for earthquake loads," Journal of Engineering, vol. 16, no. 3, pp. 5315-5336, 2021. URL: https://www.iasj.net/iasj/download/b3c73687f01d07e0

[2] G. Ahmadi, "Stochastic earthquake response of structures on sliding foundation," International Journal of Engineering Science, vol. 21, no. 2, pp. 93-102, 1983. DOI: 10.1016/0020-7225(83) 90001-0

[3] T. M. Al-Hussaini, M. C. Constantinou, V. A. Zayas, "Seismic isolation of multi-story frame structures using spherical sliding isolation systems," National Center for earthquake engineering research, 1994, pp. 1-182, URL: https://nehrpsearch.

nist.gov/static/files/NSF/PB94193745.pdf. January 20, 2021.

[4] S. Bhagat, A.C. Wijeyewickrema, "Seismic response evaluation of base-isolated reinforced concrete buildings under bidirectional excitation," Earthquake Engineering and Engineering Vibration, VOL. 16, NO. 2, PP. 365-382, 2017. DOI:10.1007/s11803-017-0387-8

[5] C. Braun, C. Butz, C. "Static and dynamic friction in curved surface sliders," IABSE Symposium, Venice 2010, pp.33-40. DOI:10.2749/222137810796025140

[6] R. I Skinner, W. H. Robinson, G. H. McVerry, "An introduction to seismic isolation," Wiley, 1993, PP. 103-110.

[7] B. Briseghella, T. Zordan, T. Liu, E. Mazzarolo, "Friction pendulum system as a retrofit technique for existing reinforced concrete building," Structural Engineering International, vol. 23 no. 2, pp. 219-224, 2013. DOI: $10.2749 / 101686613 X 13439149157759$

[8] G. Buckle, "Passive control of structures for seismic loads. Bulletin of the New Zealand Society for Earthquake Engineering," University of Nevada, Reno, USA, vol. 33, no. 3, pp. 209-221, 2000. DOI: 10.5459/bnzsee.33.3.209-2 21

[9] D. Cardone, G. Gesualdi, P. Brancato, "Restoring capability of friction pendulum seismic isolation systems," Bulletin of Earthquake Engineering, vol. 13, no. 8, pp. 2449-2480, 2015. DOI: 10.1007/s10518-014-9719-5

[10] D. Cardone, G. Palermo, M. Dolce, "Direct displacement-based design of buildings with different seismic isolation systems," Journal of Earthquake Engineering, vol. 14, no. 2, pp. 163-191, 2010. DOI: $10.1080 / 13632460903086036$

[11] Y. Chun, M. Hur, "Effects of Isolation Period Difference and Beam-Column Stiffness Ratio on the Dynamic Response of Reinforced Concrete Buildings," International Journal Concr Struct Mater, vol. 9, no. 4, pp. 39-451, 2015. DOI: $10.1007 / \mathrm{s} 40069-015-0120-9$

[12] M. C. Constantinou, I. G. Tadjbakhsh, "Hysteretic dampers in base isolation: random approach," Journal of Structural Engineering, vol. 111, 4, pp. 705-721, 1985. DOI:10.1061/(ASCE)0733-9445

[13] De Luca, L. G. Guidi, State of art in the worldwide evolution of base isolation design. Soil Dynamics and Earthquake Engineering, vol. 125, pp. 105722-34, 2019. DOI: 10.1016/j.soildyn.2019.105722

[14] M. Dolce, D. Cardone, F. Croatto, "Frictional behavior of steel-PTFE interfaces for seismic isolation. Bulletin of earthquake engineering, vol. 3, no. 1, pp. 75-99, 2005. DOI: $10.1007 / \mathrm{s} 10518-005-0187-9$

[15] Downey, M. Sadoughi, L. Cao, S. Laflamme, C. Hu, 
"Passive variable friction damper for increased structural resilience to multi-hazard excitations," ASME 2018 International Design Engineering Technical Conferences and Computers and Information in Engineering Conference, American Society of Mechanical Engineers Digital Collection, 2018, pp. 1-10. DOI: 10.1115/DETC2018-85207

[16] F. Weber, J. Distl, C. Braun, "Isolation performance assessment of adaptive behavior of Triple Friction Pendulum," Journal of Civil Engineering Research, vol. 7, no. 1, pp. 17-33, 2017. DOI: 10.5923/j.jce.20170701.03

[17] D. M. Fang, M. C. Constantinou, "Behavior of the double concave friction pendulum bearing," Earthquake engineering \& structural dynamics, vol. 35, no. 11, pp.1403-1424, 2006. DOI: 10.1002/eqe.589.

[18] K. Fujii, Y. Mogi, T. Noguchi, "Predicting Maximum and Cumulative Response of a Base-isolated Building Using Pushover Analysis," Buildings, vol. 10, no. 5, pp. 91-95, 2020. DOI: 10.3390/buildings10050091.

[19] H. M. Hilber, J. R. Thomas, Hughes, L. Robert, "Improved numerical dissipation for time integration algorithms in structural dynamics," Earthquake Engineering and Structural Dynamics, vol. 5, pp. 283-292, 1977. DOI: 10.1002/eqe.4290050306

[20] K. Ikago, N. Inoue, "Displacement Control Design Concept for Long-period Structures: Design Strategies for High-rise and Seismically Isolated Buildings Subjected to Strong Ground Motions," International Conference on Advances in Experimental Structural Engineering, vol.2015, pp. 1-5. URL:https://www.wcee.nicee.org/wcee/ article/16WCEE/WCEE2017-4123.pdf.

[21] S. Islam, S. I. Ahmad, M. Jameel, M.J. Zamin, "Seismic Base Isolation for buildings in regions of low to moderate seismicity: practical alternative design," Practice Periodical on Structural Design and Construction, vol. 17, no. 1, pp. 13-20, 2012. DOI:10.1061/(ASCE)SC.1943-557 6.0000093

[22] R. S. Jangid, "Optimum friction pendulum system for near-fault motions." "Engineering Structures, vol. 27, no. 3, pp. 349-359, 2005. DOI: 10.1016/j.engstruct.2004.09.013.

[23] R. S. Jangid, T. K. Datta, "Seismic Behaviour of Base-isolated Buildings: A state-of-the-art review," Proceedings of the Institution of Civil Engineers-Structures and Buildings, vol. 110, no. 2, pp. 186-203, 1995. DOI: 10.1680/istbu.1995.27599.

[24] R. S. Jangid, J. M. Kelly, "Base isolation for near - fault motions," Earthquake engineering \& structural dynamics, vol. 30, no. 5, pp. 691-707, 2021. URL: https://www.iitk.a c.in/nicee/wcee/article/13_2935.pdf. Retrieved on January 20, 2021.

[25] J. M. Kelly, "The role of damping in seismic isolation," Earthquake engineering \& structural dynamics, vol. 28, no. 1, pp. 3-20, 1999. DOI: 10.1002/(SICI) 1096-9845 (199901)28:1<3::AID-EQE801>3.0.CO;2-D

[26] N. Kravchuk, R. Colquhoun, A. Porbaha, "Development of a friction pendulum bearing base isolation system for earthquake engineering education," Proceedings of the 2008 American Society for Engineering Education Pacific Southwest Annual Conference, pp. 22-25, 2021. URL:https://engineering.purdue.edu/UCIST/publications/p
ublications/Base \%20isolation\%20system_Ali.pdf.

[27] D. Lee, M. C. Constantinou, "Quintuple friction pendulum isolator: behavior, modeling, and validation," Earthquake Spectra, vol. 32, no. 3, pp. 1607-1626, 2021. URL: https://www.eng.buffalo.edu/mceer-reports/15/15-0007.pd f.January 20, 2021.

[28] V. A. Matsagar, R. S. Jangid, "Influence of isolator characteristics on the response of base-isolated structures," Engineering structures, vol. 26, no. 12, pp. 1735-1749, 2021. URL:

http://nopr.niscair.res.in/bitstream/123456789/45259/1/IJE MS\%2025\%284\%29\%20346-352.pdf.

[29] F. Mazza, S. Sisinno, "Nonlinear dynamic behavior of base-isolated buildings with the friction pendulum system subjected to near-fault earthquakes." Mechanics Based Design of Structures and Machines, vol. 45 no. 3, pp. 331-344, 2017. DOI: 10.1080/15397734.2016.1277740.

[30] F. Mazza, M. Mazza, "Nonlinear seismic analysis of irregular RC framed buildings base-isolated with friction pendulum system under near-fault excitations." Soil Dynamics and Earthquake Engineering, vol. 90, pp. 299-312, 2016. DOI: 10.1016/j.soildyn.2016.08.028.

[31] N.A. Mithranjali, C.M. George, "Seismic response of multistory RC building with friction pendulum bearing system," IJRASET, vol. 5, no. 5, pp. 582-588, 2021. https://www.ijser.org/researchpaper/seismic-analysis-of-m ulti-storey-rc-buildings-supported-on-single-and-combined -base-isolation-systems.pdf.

[32] Narjabadifam, P. L. Peyman, R. Tiong, Mousavi-Alanjagh, "Effects of Inherent Structural Characteristics on Seismic Performances of Aseismically Base-Isolated Buildings," Iranian Journal of Science and Technology, Transactions of Civil Engineering, pp. 1-17, 2019. DOI: 10.1007/s4099 6-019-00317-4

[33] Nassani, Dia Eddin., M. W. Abdulmajeed, "Seismic base isolation in reinforced concrete structures," International Journal of Research Studies in Science, Engineering and Technology, vol. 2no. 2, pp. 1-13, 2019. URL: http://ijrsset.org/pdfs/v2-i2/1.pdf.

[34] N. V. Nguyen, H. P. Hoang, K. T. Huong, "Performance of Single Friction Pendulum bearing for isolated buildings subjected to seismic actions in Vietnam," IOP Conference Series: Earth and Environmental Science, vol. 143, no. 1, pp. 012048-54, 2021.https://iopscience.iop.org/article/10.1 088/1755-1315/143/1/012048/pdf.

[35] V. R. Panchal, R. S. Jangid, "Variable friction pendulum system for near - fault ground motions. Structural Control and Health Monitoring," Journal of the International Association for Structural Control and Monitoring and of the European Association for the Control of Structures, vol. 15, no. 4, pp. 568-584, 2008. DOI: 10.1002/stc. 216.

[36] S. J. Patil, G. R. Reddy, "State of art review-base isolation systems for structures," International journal of emerging technology and advanced engineering, vol. 2, no. 7, 438-453, 2013. URL: https://citeseerx.ist.psu.edu/ view doc/download?doi=10.1.1.413.6327\&rep=rep1\&type=pdf.

[37] M. A., Rincy, E. S. Saju, "Comparative Study of RC Framed Building with Isolator and Dampers," International Journal of Engineering Research and Technology, vol. 4, no. 13, pp.1-4, 2012. 
https://www.ijert.org/research/comparative-study-of-rc-fra med-building-with-isolator-and-dampers-IJERTCONV4IS 13012.pdf

[38] S. Essebier, G. Baker, "Computational techniques for nonlinear dynamics of continuous systems," Journal of Engineering Mechanics, vol.121, no. 2. Pp. 7674-7680, 1995. DOI: 10.1061/(ASCE)0733-9399 (1995)121:11(119 3).

[39] Sharma, G. R. Reddy, R. Eligehausen, K. K. Vaze, "Experimental and analytical investigation on seismic behavior of RC framed structure by pushover method," Structural engineering and mechanics: An international journal, vol. 39, no. 1, pp. 125-145, 2011. DOI: 10.12989/sem.2011.39.1.125

[40] S. Sorace, G. Terenzi, “Analysis, design, and construction of base-isolated multiple building /structures," Advances in Civil Engineering, vol. 14, no. 9, 2014. DOI: $10.1155 / 2014 / 585429$.

[41] L.Su, G.Ahmadi, I. G. Tadjbakhsh, "Comparative study of base isolation systems. Journal of engineering mechanics, vol. 115, no. 9, pp. 1976-1992, 1989. DOI: 10.1061/(ASCE)0733-9399(1989)115:9(1976)

[42] P. C. Tsopelas, M. C. Constantinou, "Reinhorn AM. 3D-BASIS-ME: Computer Program for Nonlinear Dynamic Analysis of Seismically Isolated Single and Multiple Structures and Liquid Storage Tanks," Engineerings Buffalo Education, vol. 21, no. 3, pp. 1-10, 2021.https://www.eng.buffalo.edu/mceer-reports/94/94-00 10.pdf date $8 / 8 / 2021$.

[43] J. Taylor, J. Stanton, "Final Research Report WisDOT Project ID 0092-08-13 Report No. WHRP 10-01 Friction coefficients for stainless steel /PTFE (Teflon), pp. 101-110, 2021.wisconsindot.gov/documents $2 /$ research/WisDOT-W HRP-project-0092-08-13-final-report.pdf. 08-08-2021.

[44] V. A. Zayas, S. S. Low, S. A. Mahin, “A simple pendulum technique for achieving seismic isolation," Earthquake Spectra, vol. 6, no. 2, pp. 317-333, 1990. DOI: https://doi.org/ 10.1193/1.1585573 